\title{
MATERNAL OUTCOMES OF EXPECTANT MANAGEMENT IN COMPARISON WITH INDUCTION OF LABOUR WITHIN TWENTY FOUR HOURS OF PREMATURE RUPTURE OF MEMBRANES (PROM).
}

1. MBBS, FCPS

Assistant Professor Obs \& Gynae, Nishtar Medical University, Multan. 2. MBBS, FCPS

Associate Professor Obs \& Gynae, Nishtar Medical University, Multan.

3. MBBS, FCPS

Assistant Professor Obs \& Gynae, Nishtar Medical University, Multan. 4. MBBS

Postgraduate Trainee Medical-4,

Nishtar Medical University, Multan.

\section{Correspondence Address:}

Dr. Saima Ashraf

Assistant Professor Obs \& Gynae, Nishtar Medical University, Multan. saimashahzad35177@gmail.com

Article received on: 20/09/2019

Accepted for publication:

$17 / 03 / 2020$

\section{Saima Ashraf ${ }^{1}$, Hajira Sultana ${ }^{2}$, Saima Yasmin Qadir ${ }^{3}$, Muhammad Khalid ${ }^{4}$}

ABSTRACT... Objective: this study is conducted to compare the maternal outcomes of expectant management versus induction of labour within 24 hours of premature rupture of membranes. Study Design: Randomized controlled trial. Setting: Obstetrics and Gynaecology Department, Nishtar Hospital, Multan. Period: From 15 March 2018 to 15 September 2018. Material \& Methods: A total of 130 pregnant women with parity 0 - 4 having singleton pregnancy, $\geq 37$ weeks pregnant and having premature rupture of membranes were taken in the study. Two groups were made. In Group (A) women were subjected to expectant management in which patients were observed for uterine contractions for a period of 24 hours. In Group (B) women were induced with tab dinoprostone 2 doses each $3 \mathrm{mg}$ given 6 hours apart. Results: In this study age range was from 18 to 35 years while in both groups most patients were 28 - 35 years old. In Group (A) mean gestational age was $38.246 \pm 0.84$ weeks while in Group (B) it was $37.953 \pm 0.95$ weeks. In Group $(A)$ mean parity was $1.076 \pm 1.16$ and in Group (B) it was $1.815 \pm 1.16$. in Group (A) $2.092 \pm 0.67$ hours was mean duration of PROM while in Group (B) it was $2.092 \pm 0.67$ hours. Mean BMl in Group (A) was $26.088 \pm 3.80 \mathrm{~kg} / \mathrm{m}^{2}$ and in Group (B) it was $26.361 \pm 4.33 \mathrm{~kg} / \mathrm{m}^{2}$. In Group (A), 24 patient (36.9\%) delivered vaginally while $42(64.6 \%)$ patient delivered vaginally in Group (B). 41 patients (63\%) had cesarean section in Group (A) while in Group (B) 23 patients (35.4\%) had cesarean section. Chorioamnionitis was seen in 14 patients (21.5\%) in Group (A) while 3 patients (4.6\%) had chorioamnionitis in Group (B). Conclusion: Our study concluded that induction of labour with twenty four hours of premature rupture of membranes does causes a reduction in occurrence of chorioamnionitis. By this approach patients are usually delivered within 24 hours and caesarean section rate is not increased. This approach also causes a reduction in augmentation of labour by oxytocin.

Key words: Induction of labour, maternal outcome, premature rupture of membranes,

Article Citation: Ashraf S, Sultana H, Qadir SY, Khalid M. Maternal Outcomes of Expectant Management In comparison with Induction of Labour within twenty four hours of Premature Rupture of Membranes (PROM). Professional Med J 2020; 27(8):1565-1569. DOI: 10.29309/TPMJ/2020.27.08.4182

\section{INTRODUCTION}

Premature rupture of membranes (PROM) has been traditionally defined as the rupture of fetal membranes and leakage of amniotic fluid, the event occurring before the labour starts. ${ }^{1-3}$ With the progression of pregnancy there is reduction in physical stress tolerated by fetal membranes. With advancing gestation collagen concentration falls. These factors contribute towards ensuring integrity of membranes throughout the course of pregnancy and facilitate their rupture at term.

Pre-labour rupture of membranes without spontaneous uterine contraction occurs in about $10 \%$ of all pregnancies among which almost $80 \%$ cases are found to occur at term. ${ }^{4}$ Management of PROM at term is quite a controversial issue uptil now. On one had induction of labour causes reduction in fetal and maternal sepsis but on other hand it causes an increase in caesarean section rate because of uterine hyperstimulation and fetal distress. There is conflicting data regarding whether to wait for some time before induction or to induce labour immediately. Few studies have shown that upto 48-98 hours it is safe with expectant management and this approach does not increase rate of infection. ${ }^{5}$ Induction of labour has long being associated with increased risk of cesarean section but recent studies revealed that induction of labour causes less cesarean section 
deliveries than without it. ${ }^{6}$

A study conducted by Shah $\mathrm{K}$ and his associates showed that in expectant group vaginal delivery occurred in $80 \%$ of patients while in induction group only $50 \%$ delivered vaginally. In expectant group $20 \%$ patients underwent cesarean section while in early induction group $50 \%$ of women with PROM had cesarean section. ${ }^{5}$

Another study by Maqbool S and her associates showed conflicting results. In this study in expectant group 39\% patients delivered vaginally while $67 \%$ patients had vaginal delivery in early induction group. In expectant group $61 \%$ patients had cesarean section while cesarean section rate was $33 \%$ in early induction group $25 \%$ patients had chorioamnionitis in expectant group while it was seen in only $5 \%$ patients in early induction group with PROM. ${ }^{7}$

There is conflicting data in literature regarding maternal outcomes of early induction in women with PROM and expectant management. Due to these conflicting results we have planned to compare various maternal outcomes in case of induction of labour within 24 hours of premature rupture of membranes and with expectant management. In our study chorioamnionitis is also included in outcome variables because this outcome variable in not included in previous studies done in our local population. Our study will help to select appropriate method of management in women with PROM in our population.

\section{MATERIAL \& METHODS}

This randomized controlled trial was conducted in Obstetrics \& Gynaecology Department, Nishtar Hospital Multan from $15^{\text {th }}$ March 2018 to $15^{\text {th }}$ September 2018. A total of 130 women were included after taking required approval from hospital ethical board.

18-35 years old women, para $0-4, \geq 37$ weeks pregnant according to LMP, having singleton pregnancy on ultrasound and having premature rupture of membrane $<4$ hours were included in the study. Women with PROM before 37 completed weeks, having features of chorioamnionitis, fetal distress, previous cesarean section and history of hypertension were excluded.

All patients were included in study after taking informed consent. Basic demographics (age, gestational age, BMI and parity) were recorded. Randomization was done by sequentially number opaque envelops generate from a random numbers table. The sample was divided into two groups. Sample size taken for expectant management group or Group (A) was $n_{1}=65$ and $\mathrm{n}_{2}=65$ was sample size for Group (B) or induction of labour group.

In Group (A) women were managed expectantly in which patients were observed for uterine contraction over a period of 24 hours. In Group (B) women were induced with tab. Dinoprostone $3 \mathrm{mg}$. 2 doses were given at an interval of 6 hours. Women in both groups were provided with antibiotic cover, sterile pad and fetal heart rate monitoring. Both groups were monitored for maternal outcomes i.e chorioamnionits and mode of delivery. Monitoring was done throughout labour decision of cesarean section was taken by consultant due to various indications like failed induction, fetal distress. All procedures were supervised by a consultant gynaecologist having 3 years post fellowship experience. Data regarding caesarean section, vaginal delivery and chorioamnionitis was collected by researcher herself and recorded on a specially designed proforma. Data was analyzed by SPSS version 22. Percentages and frequency was calculated for qualitative variables like vaginal delivery, poor economic status, chorioamnionitis and cesarean section. Mean and standard deviation were calculated for quantitative variables like parity, age, BMI, gestational age and duration of PROM. For comparison of maternal outcomes in both groups Chi-square test was applied taking $\leq 0.05$ as significant.

\section{RESULTS}

In this study age range was from 18-35 years. In Group (A) $29.553 \pm 1.92$ years was mean age while in Group (B) it was $30.200 \pm 2.75$ years. In Group (A) mean gestational age was 38.246 \pm 0.84 weeks while in Group (B) it was $37.953 \pm$ 
0.95 weeks. In Group (A) mean parity was 1.076 \pm 1.16 while in Group (B) it was $1.815 \pm 1.66$. In Group (A) mean duration of PROM was $2.092 \pm$ 0.67 hours and $2.092 \pm 0.67$ hours in Group $(B)$. In Group (A) mean BMI was $26.088 \pm 3.80 \mathrm{~kg} / \mathrm{m}^{2}$, in Group (B) mean BMI was $26.36 \pm 4.33 \mathrm{~kg} / \mathrm{m}^{2}$.

In both groups majority of the patients were 28-35 years old as shown in (Table-I).

\begin{tabular}{|c|c|c|c|c|}
\hline Age (Years) & \multicolumn{2}{|c|}{$\mathrm{n}=65$ (Group A) } & \multicolumn{2}{|c|}{ n=65 (Group B) } \\
\hline $18-27$ & \multicolumn{2}{|c|}{$6(9.2 \%)$} & \multicolumn{2}{|c|}{11 (16.9\%) } \\
\hline $28-35$ & \multicolumn{2}{|c|}{59 (90.8\%) } & \multicolumn{2}{|c|}{54 (83.1\%) } \\
\hline \multicolumn{5}{|c|}{$\begin{array}{l}\text { Table-I. Frequency and \%age of patients according to } \\
\text { age in both groups. }\end{array}$} \\
\hline $\begin{array}{l}\text { Vaginal } \\
\text { Delivery }\end{array}$ & $\begin{array}{l}n=65 \\
\text { Group A }\end{array}$ & $\begin{array}{l}n= \\
\text { Grol }\end{array}$ & & P-Value \\
\hline Yes & $24(36.9 \%)$ & $42(6$ & $6 \%)$ & \multirow{3}{*}{0.001} \\
\hline No & $41(63.1 \%)$ & $23(3$ & $4 \%)$ & \\
\hline Total & 65 (100\%) & $65(1$ & $\%)$ & \\
\hline
\end{tabular}

Table-II. Comparison of Vaginal Delivery in Both Groups.

\begin{tabular}{|l|c|c|c|}
\hline $\begin{array}{c}\text { Cesarean } \\
\text { Section }\end{array}$ & $\begin{array}{c}\text { n=65 } \\
\text { Group A }\end{array}$ & $\begin{array}{c}\text { n=65 } \\
\text { Group B }\end{array}$ & P-Value \\
\hline Yes & $41(63.1 \%)$ & $23(35.4 \%)$ & \\
\hline No & $24(36.9 \%)$ & $42(64.6 \%)$ & \multirow{2}{*}{0.001} \\
\hline Total & $65(100 \%)$ & $65(100 \%)$ & \\
\hline
\end{tabular}

Table-III. Comparison of Cesarean Section in both groups.

\begin{tabular}{|l|c|c|c|}
\hline $\begin{array}{c}\text { Chrioam- } \\
\text { nionitis }\end{array}$ & $\begin{array}{c}\mathbf{n = 6 5} \\
\text { Group A }\end{array}$ & $\begin{array}{c}\mathbf{n = 6 5} \\
\text { Group B }\end{array}$ & P-Value \\
\hline Yes & $14(21.1 \%)$ & $3(4.6 \%)$ & \multirow{2}{*}{0.004} \\
\hline No & $51(78.5 \%)$ & $62(95.4 \%)$ & \multirow{2}{*}{$0.004)$} \\
\cline { 1 - 2 } Total & $65(100 \%)$ & $65(100 \%)$ & \\
\hline
\end{tabular}

Table-IV. Comparison of Chorioamnionitis in both groups. $n=130$

Stratification regarding vaginal delivery and cesarean section with respect to age and duration of PROM are shown in (Table-V,VIII).

\begin{tabular}{|l|c|c|c|}
\hline \multicolumn{4}{|c|}{ For Age Group 18-27 years } \\
\hline \multicolumn{4}{|c|}{ Vaginal Delivery } \\
\cline { 1 - 3 } \multicolumn{1}{|c|}{ Group } & Yes & No & \multirow{2}{*}{ P-Value } \\
\hline A & $3(50 \%)$ & $3(50 \%)$ & \multirow{2}{*}{0.857} \\
\hline B & $5(45.5 \%)$ & $6(54.5 \%)$ & \\
\hline \multicolumn{3}{|c|}{ For Age Group 28-35 years } \\
\hline \multicolumn{1}{|c|}{ Group } & Yes & No & \multirow{2}{*}{0.000} \\
\hline A & $21(35.6 \%)$ & $38(64.5 \%)$ & \multirow{2}{*}{0.000} \\
\hline B & $37(68.5 \%)$ & $17(31.5 \%)$ & \\
\hline
\end{tabular}

Table-V. Stratification of vaginal delivery with respect to age in Group A and Group B

\begin{tabular}{|c|c|c|c|}
\hline \multicolumn{4}{|c|}{ For duration 1-2 hours } \\
\hline \multicolumn{4}{|c|}{ Vaginal Delivery } \\
\hline Group & Yes & No & P-Value \\
\hline A & $19(40.4 \%)$ & $28(59.6 \%)$ & \multirow{2}{*}{0.013} \\
\hline B & $31(66 \%)$ & $16(34 \%)$ & \\
\hline \multicolumn{4}{|c|}{ For duration $>2$ hours } \\
\hline Group & Yes & No & \multirow{3}{*}{0.044} \\
\hline A & $5(27.8 \%)$ & $13(72.2 \%)$ & \\
\hline$B$ & $11(61.1 \%)$ & 7 (38.9\%) & \\
\hline
\end{tabular}

\begin{tabular}{|c|c|c|c|}
\hline \multicolumn{4}{|c|}{ For Age Group 18-27 Years } \\
\hline \multicolumn{4}{|c|}{ Cesarean Section } \\
\hline Group & Yes & No & P-Value \\
\hline A & 3 (50\%) & $3(50 \%)$ & \multirow{2}{*}{0.857} \\
\hline B & $6(54.5 \%)$ & $5(45.5 \%)$ & \\
\hline \multicolumn{4}{|c|}{ For Age Group 28-35 Years } \\
\hline Group & Yes & No & \multirow{3}{*}{0.000} \\
\hline A & 38 (64.4\%) & 21 (35.6\%) & \\
\hline B & $17(31.5 \%)$ & $37(68.5 \%)$ & \\
\hline
\end{tabular}

\begin{tabular}{|l|c|c|c|}
\hline \multicolumn{4}{|c|}{ For duration 1-2 hours } \\
\hline \multicolumn{4}{|c|}{ Cesarean Section } \\
\hline \multicolumn{1}{|c|}{ Group } & Yes & No & P-Value \\
\hline A & $28(59.6 \%)$ & $19(40.4 \%)$ & \multirow{2}{*}{0.013} \\
\hline B & $16(34 \%)$ & $31(66 \%)$ & \\
\hline \multicolumn{3}{|c|}{ For duration $>2$ hours } \\
\hline \multicolumn{1}{|c|}{ Group } & Yes & No & \multirow{2}{*}{0.044} \\
\hline A & $13(72.2 \%)$ & $5(27.8 \%)$ & \multirow{2}{*}{$0.040)$} \\
\hline B & $7(38.9 \%)$ & $11(61.1 \%)$ & \\
\hline
\end{tabular}

Table-VIII. Stratification of Cesarean Section -with respect to duration of PROM in Group A and Group B. 


\section{DISCUSSION}

Pre-labour membrane rupture is an obstetrics phenomenon with unclear etiology, making management strategies controversial and diverse. Questions regarding management strategies arise because of concerns related to infection.

Following membrane rupture increased time period is a well known risk factor for infection. Previous research showed that if birth did not occur within twenty four hours of membrane rupture, perinatal mortality and morbidity are significantly increased. ${ }^{8,9}$ Research on factors predisposing to chorioamnionitis, postpartum endometritis, and neonatal infection show that infection risk keeps on increasing with increasing duration of membrane rupture. ${ }^{10-12}$ As the pregnancy approaches term, women usually go into spontaneous labour. But in about $8.1 \%$ of women, although membrane rupture occurs labour does not initiate within the next few hours. Since fetomaternal infection increases with increasing time period, artificial labour induction may be considered between membrane rupture and delivery. However others believe that if there is no fetomaternal compromise, it is preferable to wait for spontaneous onset of labour, because it may reduce cesarean section rate. ${ }^{13}$

In our study mostly patients were 27-35 years old and $\geq 37$ weeks pregnant in both groups. In Group (A) mean and standard duration for gestational age was $38.246 \pm 0.84$ weeks while in Group (B) it was $37.95 \pm 0.95$ weeks, not significant statistically. These findings are comparable to the study conducted by Fabiana ${ }^{14}$ in which 25 (33\%) patient were 37-38 weeks pregnant in Group (A) and in Group (B) 23 (33\%) were 37-38 weeks pregnant, again not significant statistically.

In our study induction with dinoprostone resulted in spontaneous vaginal delivery in $64.6 \%$ of patient in comparison with $36.9 \%$ of patient in expectant management group. Study conducted by Shetty et $\mathrm{al}^{15}$ show similar results. These results are also comparable to the results of study conducted by $\mathrm{Ara}^{16}$ at DOW University of Health Services and Civil Hospital, Karachi.
In our study, in induced group $35.4 \%$ patients had cesarean section in comparison with $63.1 \%$ in expectant management group. These results are statistically significant and similar to results of other studies. ${ }^{16,17}$

Chorioamnionitis was seen in $4.6 \%$ of patients in induced Group and in $21.5 \%$ of patients in expectant management group. These findings of our study are statistically significant and comparable with the findings of study conducted by Javed, ${ }^{18}$ in which induced group had a relatively lower rate of chorioamnionitis $3 \%$ as compared to $7.8 \%$ in expectant management group.

\section{CONCLUSION}

Our study concluded that with induction of labour within twenty four hours of premature rupture of membranes patients are usually delivered within 24 hours as compared to expectant management.

Active management with induction reduces oxytocin augmentation need and risk of chorioamnionitis. At the same time cesarean section rate is not increased by this approach.

\section{Copyright $@ 17$ Mar, 2020.}

\section{REFERENCES}

1. Suneela. Prelabour rupture of membranes at term: expectant management VS induction of labour. Sch. J App Med Sci. 2016;4(4D):1424-27.

2. Strauss JF. Extracellular matrix dynamics and fetal membrane rupture. Repord Sci. 2013;20(2):140-53.

3. Al Riyami N, Al-Ruheili I, Al-Shezaw F, Al-Khabori M. Extreme preterm premature rupture of membranes: risk factors and feto maternal outcomes. Oman Med J. 2013;28(2):108-11.

4. Seelbach-Goebel B. Antibiotic therapy for premature rupture of membranes and preterm labor and effect on fetal outcome. Geburtshilfe Frauenheilkd. 2013;73(12):1218-27.

5. Shah K, Doshi H. Premature rupture of membrane at term: early induction versus expectant management. J Obstet Gynaecol India. 2012;62(2):172-5.

6. Mishanina E, Rogozinska E, Thatthi T, Uddin-Khan R, Khan KS, Meads C. Use of labour induction and risk of cesarean delivery: a systematic review and metaanalysis. Can Med Assoc J. 2014;186(9):665-73. 
7. Maqbool S, Usmani AS, Bano B. Comparison of induction and expectant management of prelabour rupture of membranes at term for maternal outcome. Pak J Med Health Sci. 2014;8(3):648-51.

8. Al-Awaysheh F, Al-Qaqa K. Neonatal outcome and prenatal antibiotic treatment in premature rupture of membranes. Pak J Med Sci. 2005;21:441-4.

9. Ehernberg HM, Mercer BM. Antibiotics and the management of preterm premature rupture of the fetal membranes. Clin Perinatol 2001;28:807-18.

10. De-Aquino MM, Cecatti JG. Misoprostol versus oxytocin for labor induction in term and postterm pregnancy: randomized controlled trial. Am J Perinatol 2004;21:263-8.

11. Lyndon - Rochelle m, Holt VL, Easterling TR, Martin DP. Risk of uterine rupture during labor among women with a prior cesarean delivery. $\mathrm{N}$ Engl J Med $2001 ; 345: 3-8$.

12. Nigam, A, Singh VK, Dubay P, Pandey K, Bhagoliwal A, Prakash A. Misoprostol versus oxytocine for induction of labor at term. Int J Obstet Gynecol 2004;86:398-400.
13. Gafni A, Goeree R, Myhr TL, Hannah ME, Blackhouse $G$, Willan A et al. Induction of labour versus expectant management for prelabour rupture of the membranes at term: an economic evaluation. Can Med Assoc $\mathrm{J}$ 1997; 157:1519-25.

14. Fabiana GK, Cecatti JG, Fernanda GCS, Helaine MBPires, Mary AP. Misoprostol versus expectant management in premature rupture of membranes at term. Br J Obstet Gynecol 2005;112:1284-90.

15. Shetty A, Steward K, Stewart G, Rice P, Danielian P, Templeton A. Active management of term prelabour rupture of membranes with oral misoprostol. BJOG 2002;109:1354-8.

16. da Graca-Krupa F, Cecatti JG, de Castro-Surita FG, Milanez HM, Parpinelli MA. Misoprostol versus expectant management in premature rupture of membranes at term. BJOG 2005;112:1284-90.

17. Fisher SA, Mackenzie VP, Davies GAL. Oral versus vaginal misoprostol for induction of labor: a doubleblind randomized controlled trial. Am J Obstet Gynecol 2001;185:906-10.

18. Javaid MK, Hassan S, Tahira T. Management of prelabour rupture of membranes at term. Professional Med J 2008;15:2016-29.

\begin{tabular}{|c|c|c|c|}
\hline \multicolumn{4}{|c|}{ AUTHORSHIP AND CONTRIBUTION DECLARATION } \\
\hline Sr. \# & Author(s) Full Name & Contribution to the paper & Author(s) Signature \\
\hline 1 & Saima Ashraf & $\begin{array}{l}\text { Conception of study, Data } \\
\text { collection \& analysis. }\end{array}$ & \\
\hline 2 & & Data collection, riour reauirig. & \\
\hline 3 & Saima Yasmin Qadir & $\begin{array}{l}\text { Data analysis \& manuscript } \\
\text { writing. }\end{array}$ & \\
\hline 4 & Muhammad Khalid & $\begin{array}{l}\text { Co-oxdination among authors } \\
\text { \& Data collection. }\end{array}$ & Kact \\
\hline
\end{tabular}

